\title{
Working Length Determination in Palatal Roots of Maxillary \\ Molars
}

Melanie A. Kim-Park

Follow this and additional works at: https://scholarscompass.vcu.edu/etd

Part of the Endodontics and Endodontology Commons

(C) The Author

\section{Downloaded from}

https://scholarscompass.vcu.edu/etd/5127

This Thesis is brought to you for free and open access by the Graduate School at VCU Scholars Compass. It has been accepted for inclusion in Theses and Dissertations by an authorized administrator of VCU Scholars Compass.

For more information, please contact libcompass@vcu.edu. 


\section{School of Dentistry}

Virginia Commonwealth University

This is to certify that the thesis prepared by Dr. Melanie A. Kim-Park entitled, Working Length Determination in Palatal Roots of Maxillary Molars, has been approved by her committee as satisfactory completion of the thesis requirement for the degree of Master of Science.

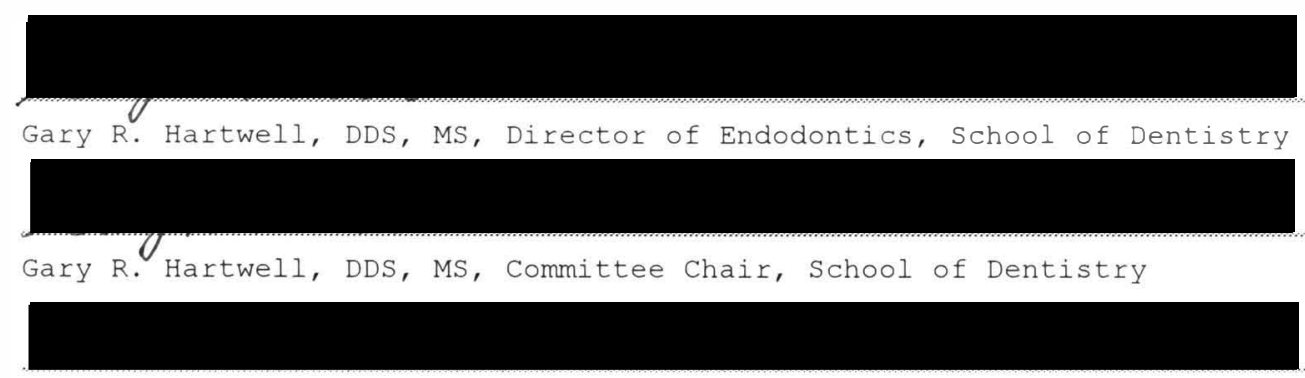

Thomas L. Walker, DDS, Committee Member, School of Dentistry

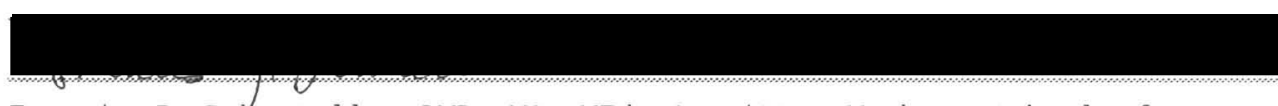

Francis J. Robertello, DMD, MS, MEd, Committee Member, School of Dentistry

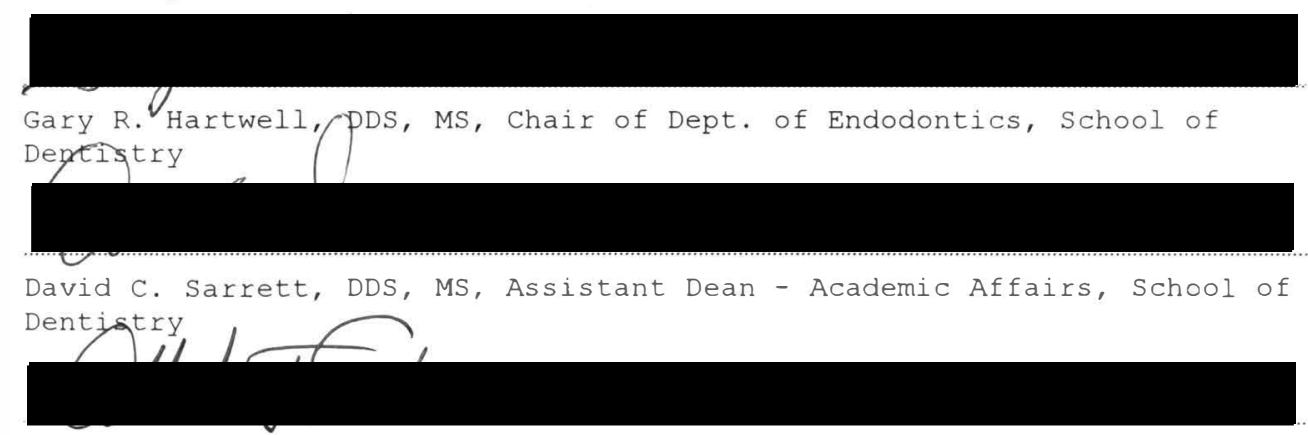

Alfred T. Sneden, PhD, Virginia Commonwealth University 
Working Length Determination in Palatal Roots of Maxillary Molars

\begin{abstract}
A thesis submitted in partial fulfillment of the requirements for the degree of Master of Science at Virginia Commonwealth University.
\end{abstract}

by

$$
\text { Melanie A. Kim-Park, }
$$

B.A., University of Virginia, May, 1993

D.D.S., Virginia Commonwealth University, May 1997

Director: Gary R. Hartwell, D.D.S., M.S.

Chairman and Professor, Department of Endodontics

Virginia Commonwealth University

Richmond, Virginia

April, 2002 
Acknowledgement

To my mentors, Drs. Gary R. Hartwell, Linda W. Baughan, Thomas L. Walker and Francis J. Robertello, thank you for all of your assistance and encouragement in this endeavor. To my parents, Young and Bong Kim, thank you for your unending love and belief in me. To my husband, Peter, thank you for your indescribable patience and love for me during the past two years of this program. Einally, to my heavenly Father, thank you for your faithfulness and for being my guide through life. 


\section{Table of Contents}

List of Tables . . . . . . . . . . . . . . . . . . . . iv List of Eigures . . . . . . . . . . . . . . . . . . . v Abstract . . . . . . . . . . . . . . . . . . . . . . . . . . vi Introduction and Purpose . . . . . . . . . . . . . . . . . . 1 Materials and Methods . . . . . . . . . . . . . . . . . 4 Results . . . . . . . . . . . . . . . . . . . 11 Discussion . . . . . . . . . . . . . . . . . . . . . . . . . . . . . Bibliography . . . . . . . . . . . . . . . . . . . . 18 Vita . . . . . . . . . . . . . . . . . . . . . . . . 22 
Table of Tables

Table

Page

1. RL-AL Difference . . . . . . . . . . . . . . . . . . 12 
Table of Figures

\section{Figure}

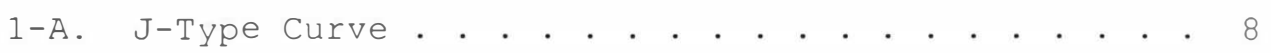
1-B. C-Type Curve . . . . . . . . . . . . . . . . . . . . . . . . 9 2. Research Design . . . . . . . . . . . . . . . . . 10 3. AL-RL Difference. . . . . . . . . . . . . . . . . . . . . 13 
Abstract

WORKING LENGTH DETERMINATION IN PALATAL ROOTS OF MAXILLARY MOLARS

By Melanie A. Kim-Park, D.D.S.

A thesis submitted in partial fulfillment of the requirements for the degree of Master of Science at Virginia Commonwealth University.

Virginia Commonwealth University, 2002

Major Director: Gary R. Hartwell, D.D.S., M.S. Chairman and Professor, Department of Endodontics

The aim of this study was to determine if a buccal curvature in the palatal roots of maxillary molars affected the clinician's ability to accurately determine working length. Twenty-seven extracted, human maxillary molars were sorted by palatal root curvatures as J- and C-type and the angle of curvature was determined. Straight-line access was made and a \#20 file was placed into the canal until the tip was visible at the apical foramen then 
withdrawn. The file, tooth and calibration wire were radiographed on one image using the RVG. Actual (file) and radiographic (tooth) lengths were determined using the RVG ruler. Radiographic length appeared shorter on average than the actual length. Canal curvatures larger than 25 degrees had differences greater than $0.5 \mathrm{~mm}$. This represents a statistically significant difference between the actual and radiographic lengths as the degree of curvature increases. There was no significant difference between the $\mathrm{J}-$ and $\mathrm{C}-$ types. 
Introduction

Working length determination for the biomechanical preparation and resultant obturation of the root canal system is one of the most critical steps in endodontics. Eailure to accurately determine the length of the tooth may lead to apical perforation with root canal preparation instruments and overextension of irrigants and obturating materials into the periradicular tissues. This could result in an increased incidence of postoperative pain and decreased success rate $(1-4)$. It may also lead to incomplete instrumentation and obturation with attendant problems, such as persistent pain and discomfort from inflamed shreds of retained pulpal tissue; or ledge formation, which may make adequate treatment or retreatment difficult or impossible (5).

It has been suggested that the accepted level for obturation of the root canal system should be between 0.5 mn and $1.0 \mathrm{~mm}$ short of the apical foramen (6) to account for the fact that the distance between the apical foramen (major diameter) and apical constriction (minor diameter) 
varied greatly in anatomic studies (6-7). In addition, the apical foramen cannot be visualized on a radiograph. Thus, the radiographic vertex is often used as a measuring point clinically, even though studies have shown that the radiographic vertex does not always coincide with the actual position of the apical foramen (8-9). This may lead to differences in radiographic and actual working lengths. Stein and Corcoran (10) found that when radiographic measurements were made, the file distance appeared $0.70 \mathrm{~mm}$ shorter on average than its actual position. They also found that the more the root end deviated from the long axis of the tooth, the more the radiographic length deviated from the actual length.

Radiographic working length determination for the palatal roots of maxillary molars may be difficult due to the superimposition of anatomic structures (ie. zygomatic arch, maxillary sinus) and a buccal curve in the apical one-third of this root. This buccal curvature occurs at least 55\% of the time in maxillary first molars and 37\% of the time in maxillary second molars (11). ElAyouti, et al. (12) found that the palatal and the mesiobuccal roots of maxillary molars tended to provide more inaccurate radiographic working length measurements than in the root 
canals of any other maxillary or mandibular molars; and that the radiographic working lengths of maxillary and mandibular molars were overextended in the apical foramen $22 \%$ of the time. This latter finding could lead to unintentional overextension of instruments and/or obturating material into the periradicular tissues. As such, an incorrect working length obtained of a threedimensional object from a two-dimensional image may directly affect the clinician's ability to adequately cleanse, shape, and obturate the root canal system. Therefore, the aim of this in-vitro study was twofold: (i) to determine if the presence of a buccal curvature in palatal roots of maxillary molars affected the ability of a clinician to accurately determine working length and (ii) to quantitatively determine the relationship between the presence of various degrees of buccal curvature in palatal roots of maxillary molars and the differences found between radiographic (RL) and actual lengths (AL). 
Materials and Methods

Thirty intact, extracted human maxillary first and second molars without visible apical root resorption were selected and radiographed from a mesiodistal direction using conventional radiographic film (Eastman Kodak Co., Ultraspeed. Rochester, NY). Radiographs were made using a paralleling technique, constant radiation exposure and developing times. Using these radiographs, the teeth were then sorted by palatal root curvatures into two descriptive categories modified from a classification previously suggested by Nagy, et al (13), J-type and C-type. Teeth were placed into the J-type group if the palatal root was straight until the apical 3-4 mm at which level a sharp buccal curvature occurred, much like in the letter " $J$ ' (Figure 1-A). Teeth were placed into the C-type group (Eigure 1-B) if the palatal root had a gradual buccal curve originating from the coronal and middle thirds of the root and extended to the root apex, much like the letter " $C$ ". Radiographic images of all teeth were then mounted and projected from a slide projector (Eastman Kodak Co., 
Ektagraphic III AMT Projector. Rochester, NY) to a standardized size ( 8.5 inches by 11 inches) and the angle of palatal root curvature was determined using Schneider's method (14).

A flat coronal reference point was created by reducing $3 \mathrm{~mm}$ of the occlusal table using a Multipurpose bur (Dentsply Maillefer. Tulsa, OK) and straight-line access was made by one operator through the crowns of each tooth sample. The coronal and middle portion of the palatal canal was then flared to a depth of approximately $12-15 \mathrm{~mm}$ with Gates-Glidden burs \#4, \#3, and \#2 (Moyco Union Broach. York, PA) using a crown-down technique and irrigating with saline. Under $3.5 \times$ magnification, canal patency was verified with a \#8 file (Flexofile, Dentsply Maillefer. Tulsa, OK) and each sample was instrumented to the verified apical foramen with a \#20 file size. Three samples were lost during this process because the apical foramen were not patent so a total of 27 samples were available for the remainder of the study.

Actual (AL) and radiographic lengths (RL) of the teeth were determined in the following manner. A \#20 NiTi file (Sureflex, Dentsply Maillefer. Tulsa, OK) was used to represent the AL. This file was introduced into the 
palatal root of the tooth until the tip of the file was visible at the apical foramen using a microscope (Global Surgical Corp., St. Louis, MO) and 10.5x magnification. An endodontic rubber file stop was used to mark the file at its coronal reference point and the file was then withdrawn and set aside.

A calibration device, consisting of a $7 \mathrm{~mm}$ length of rectangular, orthodontic arch wire (stainless steel, .016 inch $\mathrm{x} .022$ inch) was then prepared and also set aside. To minimize measurement and magnification variables, each tooth was placed in a buccal-lingual direction alongside the aforementioned \#20 NiTi file and calibration wire on a RVG sensor (Schick Technologies, Inc. Long Island City, NY) and radiographed. (Figure 2). All three objects (tooth, \#20 NiTi file and calibration wire) were placed onto the RVG sensor using a polyvinyl siloxane jig to standardize the angle and distance from the $x$-ray source.

From the image taken and using the digital ruler feature of the RVG system, the palatal root of the tooth was measured from the radiographic apex to the flat coronal reference point. This tooth measurement represented the RL. Using the digital ruler again, the distance from the tip of the \#20 NiTi file and edge of the endodontic file 
stop was measured. This file measurement represented the AL. Each RVG image was calibrated using the orthodontic arch wire of known length. All tooth samples and files were measured three times each using the digital ruler on the RVG system to the nearest tenth of a millimeter.

$$
\text { A total of } \mathrm{n}=27 \text { teeth were measured (14 type C, } 13
$$

type J). The triplicate measures of AL and RL were averaged and the difference used for analysis. Analysis of covariance was used to test for a relationship between the amount of curvature (in degrees) and the AL-RL difference (in millimeters). In addition, differences in types ( $\mathrm{J}$ vs. C) were compared. 


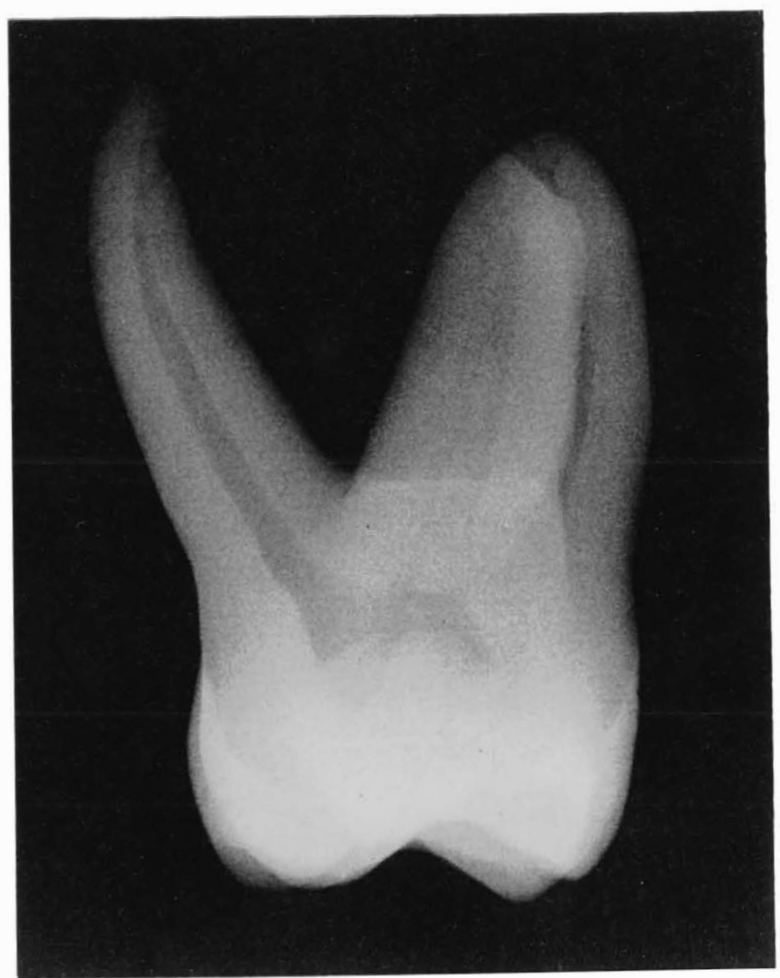

Figure 1-A. J-Type Curve 


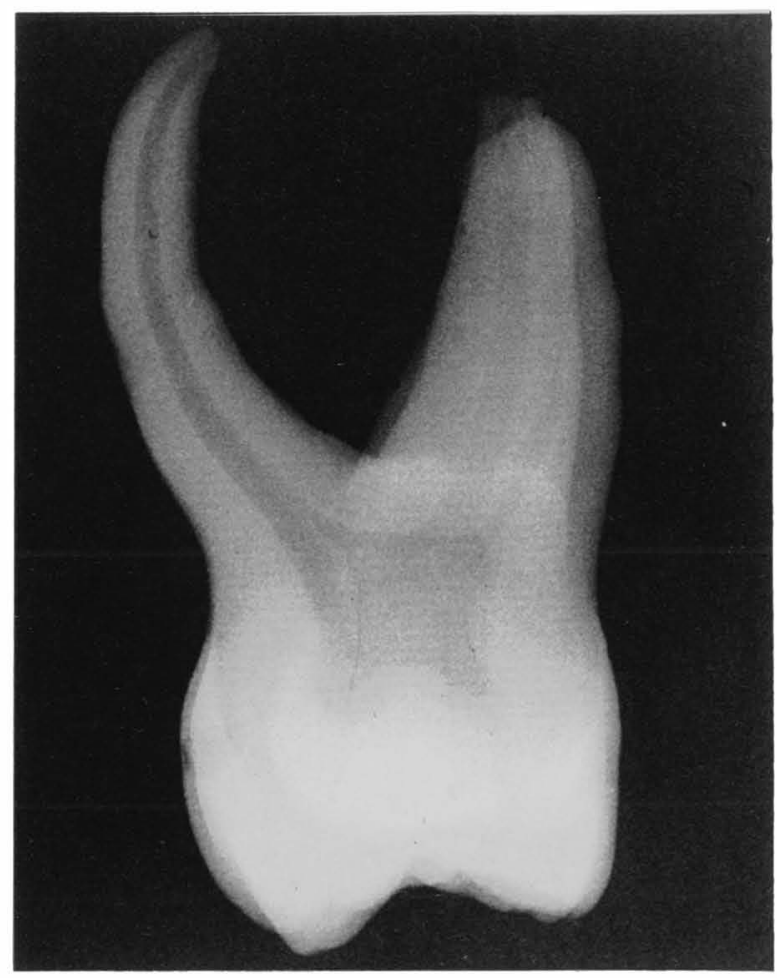

Figure 1-B. C-Type Curve 


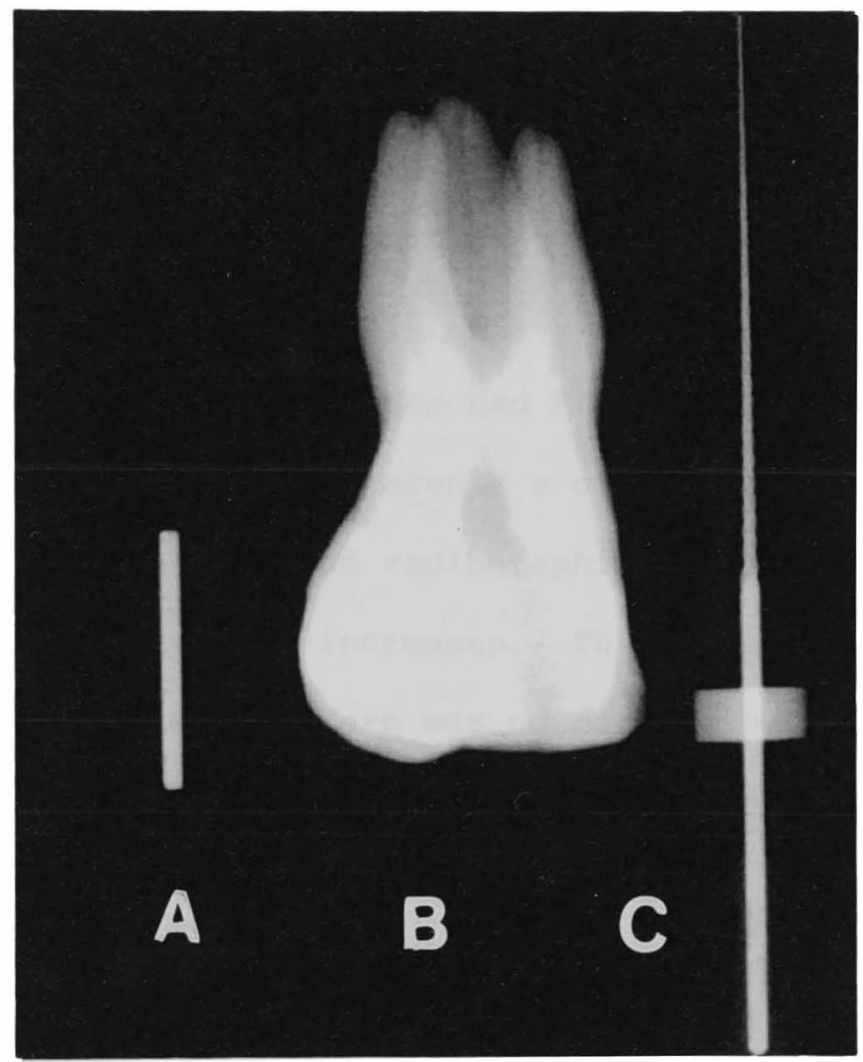

Figure 2. Research Design

Legend: $A=$ Calibration wire;

$\mathrm{B}=$ Radiographic length; $\mathrm{C}=$ Actual length 
Results

The AL and RL value differences are shown in Table 1. RL appeared shorter on average than the AL. The relationship between curvature and the AL-RL difference was a line through zero with a significant slope (estimated slope=0.0195, $\mathrm{SE}=0.00134, \mathrm{t}=14.5, \mathrm{p}<.0001)$. That is, canal curvatures larger than 25 degrees had AL-RL differences greater than $0.5 \mathrm{~mm}$. This represents a significant difference between actual and radiographic working lengths as the degree of curvature increases. This relationship is illustrated in Eigure 3. There was no canal type curvature interaction, thereby indicating no difference between the J and C types. 
Table 1. AL-RL Difference

\begin{tabular}{rcrrr}
$\begin{array}{c}\text { Curvature } \\
\text { (degrees) }\end{array}$ & $\begin{array}{c}\text { Type } \\
\text { Curve }\end{array}$ & $\mathrm{AL}(\mathrm{mm})$ & $\mathrm{RL}(\mathrm{mm})$ & $\mathrm{AL}-\mathrm{RL}$ \\
\hline 0.0 & $\mathrm{C}$ & 21.000 & 20.933 & 0.067 \\
0.0 & $\mathrm{~J}$ & 23.433 & 23.433 & 0.000 \\
11.0 & $\mathrm{C}$ & 21.833 & 21.667 & 0.167 \\
19.0 & $\mathrm{~J}$ & 20.800 & 20.733 & 0.067 \\
15.5 & $\mathrm{C}$ & 20.667 & 20.267 & 0.400 \\
19.5 & $\mathrm{~J}$ & 21.500 & 21.300 & 0.200 \\
23.0 & $\mathrm{C}$ & 20.800 & 19.867 & 0.933 \\
23.0 & $\mathrm{C}$ & 20.833 & 20.367 & 0.467 \\
23.5 & $\mathrm{C}$ & 21.067 & 20.433 & 0.633 \\
$* 25.0$ & $\mathrm{~J}$ & 21.733 & 21.333 & 0.400 \\
$* 25.0$ & $\mathrm{~J}$ & 23.533 & 23.133 & 0.400 \\
$* 25.5$ & $\mathrm{~J}$ & 22.567 & 22.067 & 0.500 \\
$* 26.0$ & $\mathrm{~J}$ & 20.567 & 20.033 & 0.533 \\
$* 30.0$ & $\mathrm{C}$ & 23.467 & 22.900 & 0.567 \\
$* 30.5$ & $\mathrm{C}$ & 22.333 & 22.033 & 0.300 \\
$* 31.0$ & $\mathrm{C}$ & 20.933 & 20.500 & 0.433 \\
$* 32.0$ & $\mathrm{C}$ & 21.200 & 20.833 & 0.367 \\
$* 32.5$ & $\mathrm{~J}$ & 20.433 & 19.867 & 0.567 \\
$* 35.0$ & $\mathrm{C}$ & 19.900 & 19.333 & 0.567 \\
$* 36.5$ & $\mathrm{~J}$ & 22.100 & 21.600 & 0.500 \\
$* 36.5$ & $\mathrm{~J}$ & 20.833 & 20.033 & 0.800 \\
$* 37.0$ & $\mathrm{C}$ & 22.167 & 21.067 & 1.100 \\
$* 39.5$ & $\mathrm{~J}$ & 21.633 & 20.867 & 0.767 \\
$* 42.5$ & $\mathrm{~J}$ & 21.000 & 20.467 & 0.533 \\
$* 43.0$ & $\mathrm{C}$ & 23.233 & 22.133 & 1.100 \\
$* 44.0$ & $\mathrm{~J}$ & 20.800 & 20.033 & 0.767 \\
$* 49.5$ & $\mathrm{C}$ & 23.833 & 22.433 & 1.400 \\
\hline & & & &
\end{tabular}

* = Statistically significant $(p<.0001)$ 


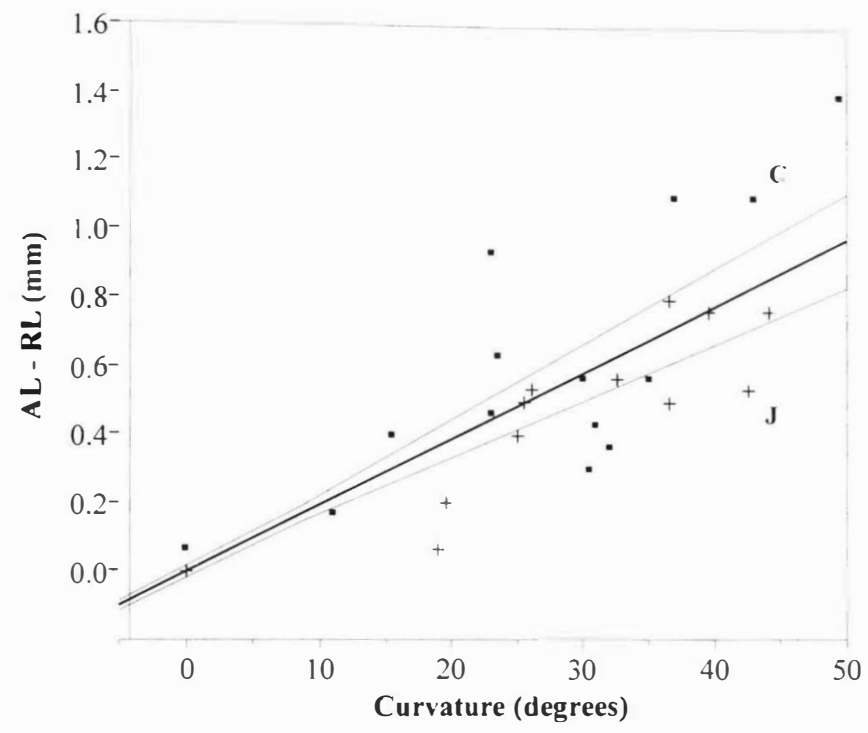

Eig. 3. AL-RL difference.

Legend: $\quad=\mathrm{C}$ and $+=\mathrm{J}$;

solid line = best fit, dotted lines $=+1 \mathrm{SD}$ 


\section{Discussion}

Maxillary molars can pose a challenge to clinicians for various reasons. Although many studies have looked at the mesiobuccal root of maxillary molars, the palatal root has not received as much attention, and in particular, no study has looked specifically at palatal root anatomy in regards to accurately determining working length for canal instrumentation and obturation. In this study, extracted maxillary molars were studied to see if a buccal curve in the palatal root affected the ability of a clinician to accurately determine working length.

In examining the teeth, it was discovered that buccal curvatures of the palatal root either occurred abruptly in the apical third of the root or were a graduate curve beginning in the coronal or middle third of the root and ending at the root apex. It was decided to qualitatively categorize them as $J$ and $C$ type based on the location of the curve to see if there was any difference between the two types. Schneider's angle was used to quantitatively describe the degree of curvature present and to determine 
if a relationship existed between curvature and the AL-RL difference.

In this study, results showed a significant difference between actual and radiographic working lengths as the degree of curvature increased. RL appeared on the average to be shorter than the AL. Regardless of the type of curve (J vs. C types), canal curvatures larger than 25 degrees had AL-RL differences over $0.5 \mathrm{~mm}$. There were no significant differences observed between the $J$ or $C$ type curves. This finding tends to support the work of Stein and Corcoran (10) who found that radiographic lengths appeared $0.7 \mathrm{~mm}$ shorter than their actual lengths. It also supports the findings of ElAyouti, et al. (12) who concluded that the palatal and mesiobuccal roots of maxillary molars tended to provide more inaccurate RL measurements than other root canals of molars. The findings in the present study may be in part due to two factors. First, because the curvature in the palatal root is typically viewed in a buccal-lingual orientation, a geometric illusion may be created that makes the viewed length appear shorter than its actual length. Secondly, it is well known that the apical foramen does not always coincide with the radiographic vertex (8-9), thus solely 
using a radiographic length to determine working length may produce inadvertent overextension of instruments into the periradicular tissues in many cases (12).

$$
\text { Radiovisiography (RVG) was used in this study in }
$$

conjunction with the digital ruler feature to measure all lengths in this study. The research design of placing all three objects (file, tooth, and calibration wire) on one sensor and measuring in triplicate was to eliminate operator variability and bias in measurement procedures and to standardize measurement units to a tenth of a millimeter. Ellingsen, et al. (15) found that when determining working length with \#8 and \#10 files, RVG in positive/negative zoom mode was equal in accuracy to Dspeed film. Piepenbring, et al. (16) further found that the larger the file size, the less deviation occurred from the known lengths on a RVG image. Therefore a larger file size of \#20 was selected in this study to measure AL and all measurements were taken in a positive/negative zoom mode using the RVG system. Finally, Burger, et al. (17) showed that there was no improvement in length estimation when making additive multiple point measurements versus a single point measurement on RVG images. Therefore, in this 
study all RVG measurements were made using single point measurements for each object.

In conclusion, the results of this study suggests that due to a frequent buccal curvature in the palatal roots of maxillary molars, the ability of a clinician to accurately determine working length based solely on radiographic interpretation may be impaired. The study also suggests that this discrepancy between $A L$ and RL will increase significantly as the degree of curvature increases and that with canal curvatures larger than 25 degrees, the AL-RL difference will be greater than $0.5 \mathrm{~mm}$ in the palatal root of maxillary molars. Clinically, this and other evidence from previous studies (6-12) point out the limitations in using radiographs as a sole means of determining working length. Further research is needed to determine if the combined use of radiographs and adjuncts such as electronic apex locators can more accurately determine the ideal terminus (i.e. the apical constriction) for root canal instrumentation and obturation in the palatal roots of maxillary molars. 
Bibliography 
Bibliography

1. Seltzer S, Bender IB. Endodontic failure and analysis based on clinical roentgenographic and histologic findings: parts I and II. Oral surg Oral Med Oral Pathol 1967;23:500-30.

2. Swartz DB, Skidmore AE, Griffin JA. Twenty years of endodontic success and failure. J Endodon 1983;9:198202 .

3. Sjögren U, Hagglund B, Sundquist G, Wing K. Factors affecting the long-term results of endodontic treatment. J Endodon 1990;16:498-504.

4. Smith CS, Setchell DJ, Harty FJ. Factors influencing the success of conventional root canal therapy-a five year retrospective study. Int Endod J 1993;26:321-33.

5. Sinai I, Seltzer S, Soltanoff W, Goldberg A, Bender IB. Biologic aspects of endodontics: part II. Periapical tissue reactions to pulp extirpation. Oral Surg Oral Med Oral Pathol 1967; 23:664-79.

6. Kuttler Y. Microscopic investigation of root apices. J Am Dent Assoc 1955;50:544-52.

7. Dummer PMH, MCGinn JH, Rees DG. The position and topography of the apical canal constriction and apical foramen. Int Endod J 1984;17:192-8. 
8. Burch JG, Hulen S. The relationship of the apical foramen to the anatomic apex of the tooth root. Oral Surg Oral Med Oral Pathol 1972;34:262-8.

9. Pineda F, Kuttler Y. Mesiodistal and buccolingual roentgenographic investigation of 7,275 root canals. Oral Surg Oral Med Oral Pathol 1972;33:101-10.

10. Stein TJ, Corcoran JF. Radiographic "working length" revisited. Oral Surg Oral Med Oral Pathol $1992 ; 74: 796-800$.

11. Pineda F. Roentgenographic investigation of the mesiobuccal root of the maxillary permanent first molar. Oral Surg Oral Med Oral Pathol 1973:36;253.

12. ElAyouti A, Weiger R, Löst C. Frequency of overinstrumentation with an acceptable radiographic working length. J Endodon 2001;27:49-52.

13. Nagy CD, Szabo J, Szabo J. A mathematically based classification of root canal curvatures on natural human teeth. J Endodon 1995;21:557-60.

14. Schneider SW. A comparison of canal preparations in straight and curved root canals. Oral Surg Oral Med Oral Pathol 1971;32:271-5.

15. Ellingsen MA, Harrington GW, Hollender LG. Radiovisiography versus conventional radiography for detection of small instruments in endodontic length determination. Part I. In vitro evaluation. J Endodon 1995:21;326-31.

16. Piepenbring ME, Potter BJ, Weller RN, Loushine RJ. Measurement of endodontic file lengths: a density profile plot analysis. J Endodon 2000:26;615-8. 
17. Burger CL, Mork TO, Hutter JW, Nicoll B. Direct direct radiography versus conventional radiography for estimation of canal length in curved canals. J Endodon $1999 ; 25: 260-3$. 
Vita

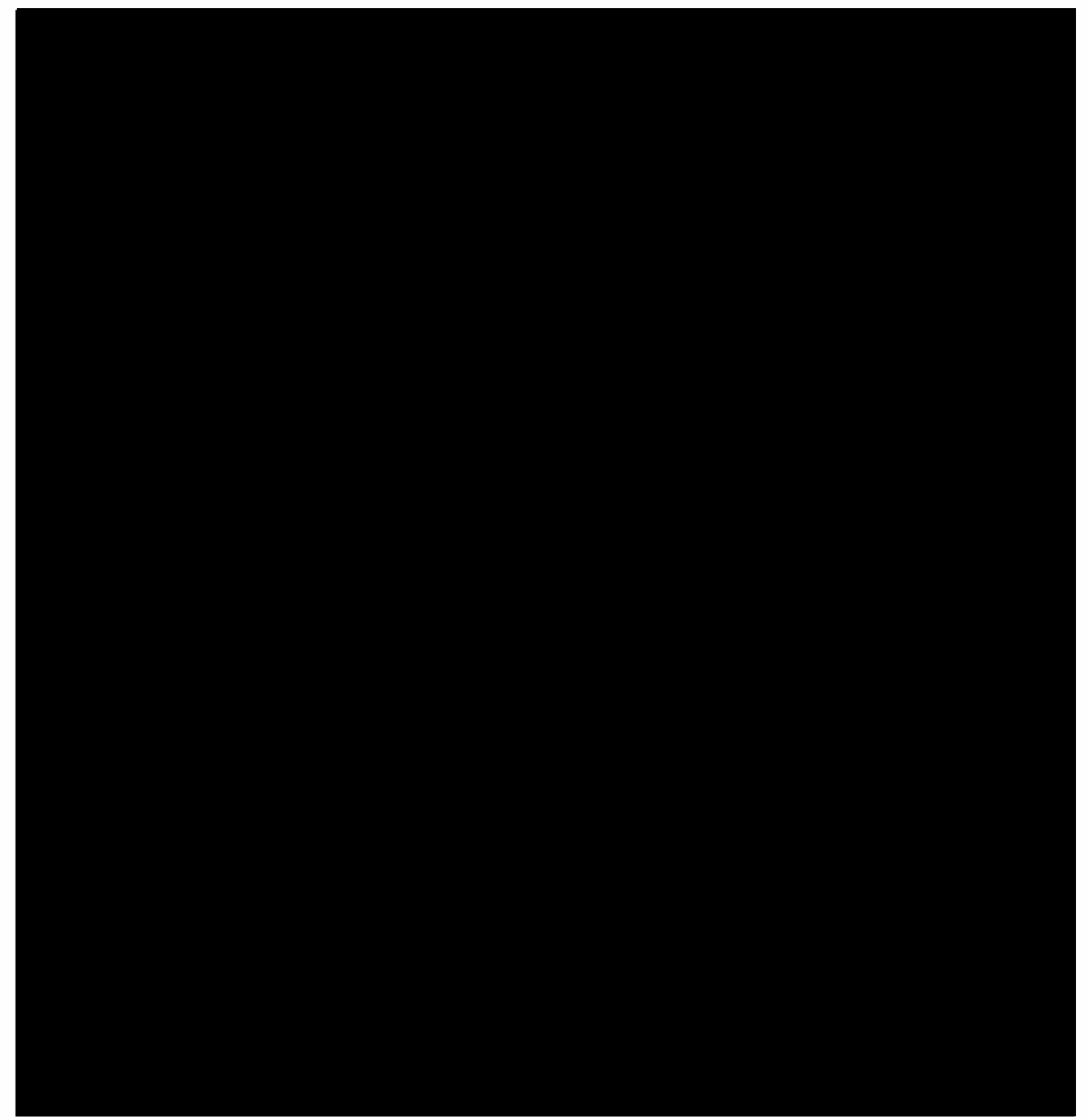

